\title{
The bilingual advantage in novel word learning
}

\author{
Margarita Kaushanskaya \\ University of Wisconsin, Madison, Wisconsin \\ AND \\ VioRica Marian \\ Northwestern University, Evanston, Illinois
}

\begin{abstract}
The present study examined whether bilingualism facilitates acquisition of novel words in adults with different language histories. Word-learning performance was tested in monolingual English speakers, early EnglishSpanish bilinguals, and early English-Mandarin bilinguals. Novel words were phonologically unfamiliar to all participants, and they were acquired in association with their English translations. At testing, both bilingual groups outperformed the monolingual group. These findings indicate that bilingualism facilitates word-learning performance in adults, and they suggest a general bilingual advantage for novel word learning.
\end{abstract}

The results of recent research on interactions between linguistic experience and cognitive function suggest that bilingualism can positively influence nonlinguistic cognition (e.g., Bialystok, 1999; Bialystok, Craik, Klein, \& Viswanathan, 2004; Colzato et al., 2008; Costa, Hernández, \& Sebastián-Gallés, 2008), as well as some aspects of linguistic processing (e.g., Bialystok, Luk, \& Kwan, 2005; Bruck \& Genesee, 1995). In the nonlinguistic domain, bilingualism has been shown to facilitate selective attention and inhibitory control in both children (Bialystok \& Martin, 2004) and adults (Bialystok, Craik, \& Ryan, 2006). In the linguistic domain, bilingualism has been shown to facilitate children's performance on metaphonological tasks that probe the ability to analyze and manipulate language in terms of discrete phonemic units (Bialystok, Majumder, \& Martin, 2003; Bruck \& Genesee, 1995). The goal of the present study was to examine the effects of bilingualism on adults' ability to acquire new words.

Similar to the effects of bilingualism on phonological awareness and inhibitory control, early exposure to two languages may facilitate word learning. Since early bilingualism appears to facilitate some aspects of phonological processing (see, e.g., Bialystok et al., 2003), it is possible that early exposure to two languages also facilitates the ability to acquire novel phonological forms. Two previous studies tested the impact of language-learning experience on vocabulary acquisition (Papagno \& Vallar, 1995; Van Hell \& Mahn, 1997); however, neither examined the effects of early bilingual exposure on word learning. Instead, both Papagno and Vallar (1995) and Van Hell and Mahn (1997) tested vocabulary acquisition in multilingual adults who had acquired their various second (and third) languages via classroom exposure. The vocabulary-learning paradigm in both studies resembled paired-associate learning, in which the novel word is presented in association with its native-language translation. This method is frequently used in classroom foreign-language teaching; therefore, it is possible that the superior performance that was observed for experienced (vs. inexperienced) language learners in both studies resulted from a transfer of classroom learning strategies, and not from bilingualism per se. It remains unknown whether naturalistic acquisition of two languages early in life yields bilingual advantages on paired-associate learning tasks in adults.

The present study addressed two goals. First, we aimed to examine the effects of early exposure to two languages on word-learning ability in adults. We therefore examined word learning in adults who had acquired their two languages very early in life. Second, we were interested in examining how general a bilingual advantage for wordlearning (if revealed) is. We therefore examined whether experience with two phonologically and orthographically similar languages (e.g., English and Spanish) and two phonologically and orthographically different languages (e.g., English and Mandarin Chinese) would both yield word-learning advantages.

Crosslinguistic similarity between the two languages that are known to bilinguals may be an important factor in shaping the bilingual advantage for word learning. Although the bilingual advantage on nonlinguistic tasks does not rely on the specific combination of languages that are spoken by bilinguals (see, e.g., Bialystok et al., 2004), the bilingual advantage on phonological tasks appears to depend on the characteristics of the two languages. For instance, Bialystok et al. (2003) and Bialystok et al. (2005) demonstrated that performance on phonological-awareness tasks is facilitated in only those bilinguals whose two languages share the same print-to-

M. Kaushanskaya, kaushanskaya@wisc.edu 
sound conversion principle (e.g., alphabetic systems of English and Hebrew) and/or the same writing system (e.g., the Roman alphabet of English and Spanish). Conversely, bilinguals whose languages do not share the same print-to-sound conversion system (e.g., English and Cantonese) do not show an advantage over monolinguals on phonological-awareness measures. Because word learning is a phonological task, it is possible that the effects of bilingualism on word-learning performance are subject to the same constraints that phonological-awareness tasks are. Previous studies on word learning in bilinguals (Papagno \& Vallar, 1995; Van Hell \& Mahn, 1997) focused on multilinguals who spoke two or more related languages that share an alphabet; therefore, it is unclear whether the advantage for word learning can arise independently of script differences, or whether it can be observed only in bilinguals whose two languages share phonological and orthographic properties.

It thus remains unknown whether the bilingual advantage on word-learning tasks generalizes to early bilinguals who learned their second language (L2) in a natural immersion environment, and to bilinguals whose languages do not share an alphabet. The present study examined the effect of different types of bilingualism on word learning in adults by comparing English monolinguals to English-Spanish bilinguals and English-Mandarin bilinguals. English-Spanish bilinguals were chosen because English and Spanish share the Roman alphabet; English-Mandarin bilinguals were chosen because the alphabetic English and the logographic Mandarin have distinct script systems.

Since word learning is facilitated by phonological familiarity (see, e.g., Ellis \& Beaton, 1993), the phonological structure of novel words was carefully manipulated to be equally unfamiliar to all participants, monolingual and bilingual. It is impossible to equate the degree of phonological overlap among three natural languages; therefore, we designed an artificial phonological system that would overlap with English, Spanish, and Mandarin to similar degrees. Because a fully familiar phonological system would be too easy to acquire, we introduced a level of difficulty into the task by incorporating phonemes that would not be familiar to any of the participants. Introduction of unfamiliar phonemes also served to make the task more ecologically valid, since acquisition of a new language often entails exposure to unfamiliar phonemes.
In sum, the present study tested (1) whether early bilingual experience facilitates word learning later in life, and (2) whether experience with two languages that do not share an alphabet or print-to-sound conversion principles (English and Mandarin) yields a similar advantage to that yielded by experience with two languages that share an alphabet and print-to-sound conversion principles (English and Spanish).

\section{METHOD}

\section{Participants}

Sixty participants were recruited for the study: 20 English-Spanish bilinguals, 20 English-Mandarin bilinguals, and 20 English-speaking monolinguals. Participant characteristics are presented in Table 1. The three groups were comparable in terms of age and education levels. In order to ensure high and equal levels of native-language knowledge across the three groups, standardized English vocabulary tests were administered to all participants. The three groups did not differ in performance on either the receptive (Peabody Picture Vocabulary Test-III; Dunn \& Dunn, 1997) or the expressive (Expressive Vocabulary Test; Williams, 1997) vocabulary tests. Because word-learning ability has been shown to correlate with phonological working memory capacity (see, e.g., Gupta, 2003), a measure of phonological working memory was also administered to all participants. Specifically, participants completed the digit-span subtest of the Comprehensive Test of Phonological Processing (Wagner, Torgesen, \& Rashotte, 1999). Crossgroup comparisons revealed that the three groups of participants performed similarly on the digit-span measure.

All participants were native speakers of English. The two bilingual groups consisted of native speakers of English who had acquired either Spanish or Mandarin as a second language. Language-proficiency, learning-history, and current-exposure data were obtained from all bilingual participants using the Language Experience and Proficiency Questionnaire (Marian, Blumenfeld, \& Kaushanskaya, 2007), and they are presented in Table 2. Although both groups acquired L2 very early in life, English-Mandarin bilinguals acquired their L2 at a younger age than did English-Spanish bilinguals. Both groups of participants indicated similarly high L2-proficiency levels and comparable preference levels regarding the use of their L2.

Participants' learning-history data revealed that English-Spanish and English-Mandarin bilinguals were exposed to their L2 primarily in the family context, and they had spent very little time exposed to formal L2 schooling. Data were collected regarding the relative contribution of different learning environments to L2 acquisition. In both groups of bilinguals, participants reported that on a scale of 0 (not a contributor) to 10 (most important contributor), exposure to family members was the most important contributor to their L2 acquisition, whereas schooling was the least important contributor. Data regarding participants' current exposure to L2 revealed that at the time of the study, participants were exposed to L2 mostly in the context of family

Table 1

Participant Data Across Three Groups

\begin{tabular}{|c|c|c|c|c|c|c|c|c|c|}
\hline & \multicolumn{2}{|c|}{ Monolinguals } & \multicolumn{2}{|c|}{$\begin{array}{l}\text { English-- } \\
\text { Spanish } \\
\text { Bilinguals }\end{array}$} & \multicolumn{2}{|c|}{$\begin{array}{l}\text { English- } \\
\text { Mandarin } \\
\text { Bilinguals }\end{array}$} & \multirow[b]{2}{*}{$d f$} & \multirow[b]{2}{*}{$\Gamma$} & \multirow[b]{2}{*}{$p$} \\
\hline & $M$ & $S E$ & $M$ & $S E$ & $M$ & $S E$ & & & \\
\hline Age & 21.64 & 0.62 & 20.83 & 0.63 & 21.10 & 0.63 & 2,55 & 0.43 & .65 \\
\hline Years of education & 15.55 & 0.46 & 14.74 & 0.47 & 14.69 & 0.57 & 2,52 & 1.04 & .36 \\
\hline PPVT-III (percentile) & 84.65 & 4.39 & 84.81 & 4.50 & 80.92 & 4.50 & 2,55 & 0.24 & .79 \\
\hline EVT (percentile) & 89.85 & 4.48 & 81.66 & 4.60 & 93.00 & 4.73 & 2,54 & 1.59 & .21 \\
\hline Digit span (percentile) & 77.55 & 4.41 & 74.95 & 4.52 & 76.67 & 4.64 & 2,57 & 0.09 & .92 \\
\hline
\end{tabular}

Note-PPVT-III, Peabody Picture Vocabulary Test-III; EVT, Expressive Vocabulary Test; Digit span, digit span subtest of Comprehensive Test of Phonological Processing. 
Table 2

Second-Language (L2) Acquisition and L2-Use Data for Bilingual Participants

\begin{tabular}{|c|c|c|c|c|c|c|}
\hline & \multicolumn{2}{|c|}{$\begin{array}{c}\text { English-- } \\
\text { Spanish } \\
\text { Bilinguals }\end{array}$} & \multicolumn{2}{|c|}{$\begin{array}{l}\text { English- } \\
\text { Mandarin } \\
\text { Bilinguals }\end{array}$} & \multirow[b]{2}{*}{$t(39)$} & \multirow[b]{2}{*}{$p$} \\
\hline & $M$ & $S E$ & $M$ & $S E$ & & \\
\hline L2-acquisition age & 5.44 & 0.82 & 2.21 & 0.80 & 3.18 & .05 \\
\hline Self-rated L2 proficiency ( $0-10$ scale) & 8.00 & 0.34 & 7.47 & 0.33 & 0.62 & .28 \\
\hline Preference of L2 use (percentage) & 26.95 & 5.84 & 24.89 & 4.78 & 0.27 & .79 \\
\hline Years of L2 exposure in family contexts & 12.92 & 2.34 & 14.47 & 2.08 & 1.02 & .12 \\
\hline Years of L2 exposure through formal schooling & 3.57 & 1.17 & 5.58 & 1.08 & 1.26 & .22 \\
\hline \multicolumn{7}{|l|}{ Contribution of family to L2 acquisition } \\
\hline$(1=$ not a contributor, $10=$ very important contributor $)$ & 6.28 & 1.07 & 7.16 & 0.86 & 0.64 & .52 \\
\hline \multicolumn{7}{|l|}{ Contribution of formal schooling to L2 acquisition } \\
\hline$(1=$ not a contributor, $10=$ very important contributor $)$ & 3.83 & 0.86 & 3.95 & 0.74 & 0.10 & .92 \\
\hline \multicolumn{7}{|l|}{ Degree of daily exposure to L2 in family contexts } \\
\hline$(1=$ none, $10=$ always $)$ & 4.11 & 1.09 & 5.16 & 0.84 & 0.77 & .45 \\
\hline \multicolumn{7}{|l|}{ Degree of daily exposure to L2 in formal schooling contexts } \\
\hline$(1=$ none, $10=$ always $)$ & 1.50 & 0.43 & 1.32 & 0.42 & 0.29 & .78 \\
\hline Percentage of daily exposure to L2 & 11.79 & 2.80 & 9.58 & 2.08 & 0.15 & .58 \\
\hline
\end{tabular}

rather than in the context of formal schooling. The overall exposure to L2 at the time of the study was comparable across the two groups. The relatively low percentages of current L2 exposure (11.79\% for English-Spanish bilinguals and $9.58 \%$ for English-Mandarin bilinguals) resulted from the fact that at the time of the study, participants were university students who interacted mostly in English.

\section{Materials}

An artificial phonological system was constructed to include four English phonemes (two vowels, $/ \Lambda /$ and $/ \varepsilon / ;$ two consonants, $/ \mathrm{f} / \mathrm{and} / \mathrm{n} /$ ) and four non-English phonemes (two vowels, $/ \mathrm{u} /$ and $/ \mathrm{Y} /$; two consonants, $/ \mathrm{t} /$ and $/ \chi /$ ). The eight phonemes were used to construct 48 disyllabic novel words. Novel words were paired with their English "translations." All 48 English translations referred to concrete, imageable objects with high-frequency English names. None of the novel words were phonologically similar to their English translations.

None of the four non-English phonemes in the artificial phonemic inventory belonged to either the Spanish (see, e.g., MartínezCeldrán, Fernández-Planas, \& Carrera-Sabaté, 2003) or the Mandarin (see, e.g., Wan \& Jaeger, 2003) phonological system. Neither Spanish nor Mandarin possesses a high central rounded vowel $/ \mathrm{u} /$ or a high near-front rounded vowel $/ \mathrm{Y} /$ (although both languages include high vowels $/ \mathbf{i} /$ and $/ \mathrm{u} /$ ). Similarly, neither Spanish nor Mandarin includes an alveolar retroflex stop $/ \mathrm{t} /$ and the uvular fricative $/ \chi /$, but both incorporate the dental and/or alveolar stop/t/ and have the velar stop $/ \mathrm{k} /$ and the velar fricative $/ \mathrm{x} /$. The four non-English sounds are therefore equally unfamiliar to speakers of Spanish and Mandarin.

A monolingual native speaker of English produced all the stimuli after extensive training on their pronunciation. Perceptual ratings were obtained for the novel words to ensure that the novel words were dissimilar from English, Spanish, and Mandarin phonological systems. Ten monolingual speakers of English rated the stimuli for their "wordlikeness" in regards to English, 10 English-Spanish bilinguals rated the stimuli for their "wordlikeness" in regards to Spanish, and 10 English-Mandarin bilinguals rated the stimuli for their "wordlikeness" in regards to Mandarin Chinese. Raters were different from the participants who were recruited for the wordlearning experiment, but they represented the same populations. Raters listened to each novel word and judged it on a Likert scale $[1=$ does not sound like a possible English (or Spanish or Mandarin) word, 7 = sounds like a possible English (or Spanish or Mandarin) word]. Novel words were rated low in terms of wordlikeness in all three languages. Analyses revealed comparable ratings for the likelihood that the nonwords sounded English $(M=2.78, S E=$ $0.14)$, Spanish $(M=2.82, S E=0.13)$, or Mandarin $(M=2.49$, $S E=0.09)(p>.1)$.

\section{Procedure}

Vocabulary learning. Participants heard the novel word pronounced twice over headphones, and they saw its written English translation on the computer screen. Participants were instructed to repeat the novel word and its English translation out loud three times. Each pair was presented twice during the learning phase. Learning was self-paced.

Vocabulary testing. Participants' memory was tested using recall and recognition tasks both immediately after learning and after a 1-week delay. During recall testing, participants heard the novel word and pronounced its English translation. During recognition testing, participants heard the novel word and chose the correct English translation from five options that were listed on the computer screen. The five options included the correct English translation and four foils. Of the four foils, two were English translations for other novel words, one was an English word that was semantically related to the correct English translation, and one was an unrelated English word.

Testing involved recall of English translations and not production of novel words, for two reasons. First, production of phonologically unfamiliar novel words was unduly difficult and yielded floor performance effects during piloting. Second, we were more interested in the effects of bilingualism on the acquisition of word meanings than on pronunciation skills.

\section{Analyses}

Recognition and recall data were each analyzed using a $2 \times 3$ ANOVA, with group (monolinguals, English-Spanish bilinguals, English-Mandarin bilinguals) as a between-subjects independent variable, and testing session (immediate vs. delayed) as a withinsubjects independent variable. Both by-subject $\left(F_{1}\right)$ and by-item $\left(F_{2}\right)$ analyses were conducted. Because groups differed in their age of acquisition (AoA) of L2, analyses of covariance that factored out L2 AoA were also performed.

\section{RESULTS}

The results of recognition and recall comparisons are presented in Figure 1. A $2 \times 3$ ANOVA for recognition data revealed a main effect of group $\left[F_{1}(2,55)=4.86\right.$, $M S_{\mathrm{e}}=0.04, p<.01, \eta_{\mathrm{p}}^{2}=.15 ; F_{2}(2,141)=14.00, M S_{\mathrm{e}}=$ $0.03, p<.001, \eta_{\mathrm{p}}^{2}=.17$ ], with English-Spanish bilinguals $(M=0.73, S E=0.03)$ and English-Mandarin bilinguals $(M=0.74, S E=0.03)$ demonstrating accuracy rates that were higher than those of monolinguals $(M=$ 


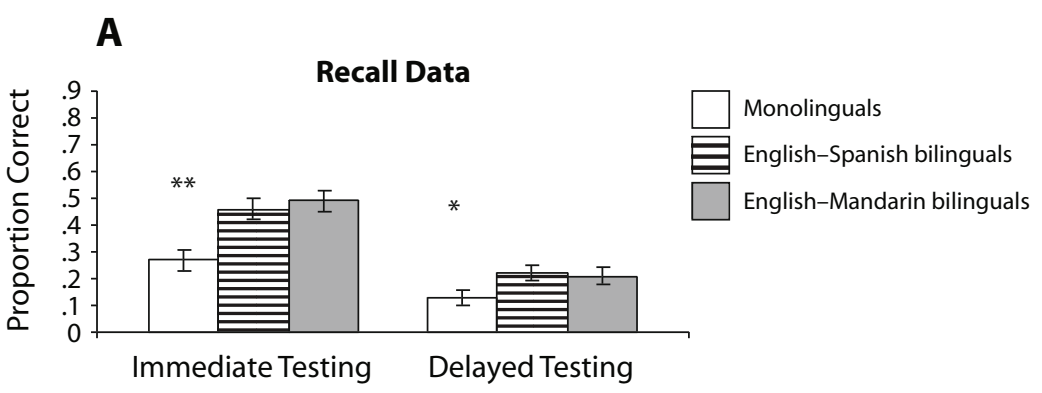

B

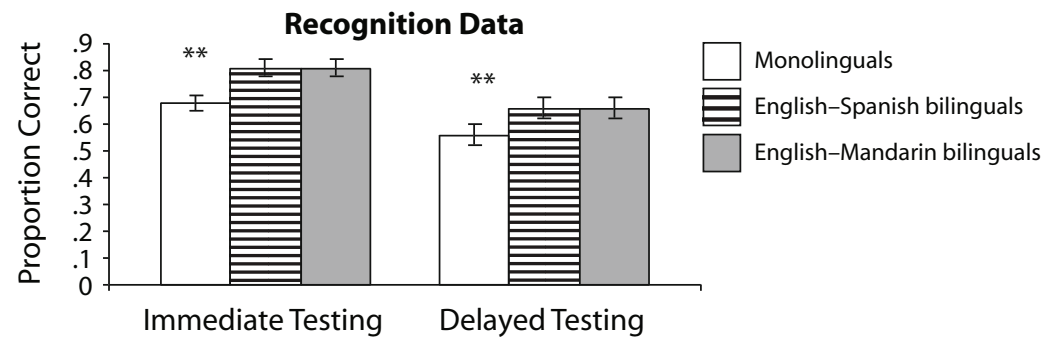

Figure 1. Mean performance accuracy (proportion correct) on recall (A) and recognition (B) measures across the three groups for immediate and delayed testing (error bars represent $S E$ values). All univariate comparisons across groups were significant, with English-Mandarin bilinguals and English-Spanish bilinguals outperforming monolinguals but not differing from each other. ${ }^{*} p<.05 .{ }^{* * *} p<.01$.

0.61, $S E=0.03)$ (all Bonferroni post hoc $p$ s $<.01)$. The analysis also revealed a main effect of testing session $\left[F_{1}(1,55)=1,423.05, M S_{\mathrm{e}}=0.01, p<.0001, \eta_{\mathrm{p}}^{2}=.96\right.$; $\left.F_{2}(1,141)=5,960.75, M S_{\mathrm{e}}=0.01, p<.001, \eta_{\mathrm{p}}^{2}=.98\right]$, with participants performing more accurately during immediate testing $(M=0.76, S E=0.02)$ than during delayed testing $(M=0.63, S E=0.02)$. Follow-up univariate ANOVAs with group as the independent variable revealed that the two bilingual groups outperformed the monolingual group on both immediate (Bonferroni post hoc $p$ s $<$ .01 ) and delayed (Bonferroni post hoc $p$ s $<.01$ ) recognition measures, but did not differ from each other.

A $2 \times 3$ ANOVA for recall data revealed a main effect of group $\left[F_{1}(2,54)=6.36, M S_{\mathrm{e}}=0.04, p<.01, \eta_{\mathrm{p}}^{2}=\right.$ $\left..19 ; F_{2}(2,141)=13.41, M S_{\mathrm{e}}=0.04, p<.001, \eta_{\mathrm{p}}^{2}=.16\right]$, with English-Spanish bilinguals $(M=0.34, S E=0.03)$ and English-Mandarin bilinguals $(M=0.35, S E=0.03)$ demonstrating accuracy rates that were higher than those of monolinguals $(M=0.20, S E=0.03)$. The analysis also revealed a main effect of testing session $\left[F_{1}(1,54)=\right.$ $196.67, M S_{\mathrm{e}}=0.01, p<.0001, \eta_{\mathrm{p}}^{2}=.79 ; F_{2}(1,141)=$ 653.97, $\left.M S_{\mathrm{e}}=0.01, p<.001, \eta_{\mathrm{p}}^{2}=.82\right]$, with participants performing more accurately during immediate testing $(M=0.41, S E=0.03)$ than during delayed testing $(M=0.18, S E=0.02)$. In addition, a significant twoway interaction was observed between testing session and group $\left[F_{1}(2,54)=7.13, M S_{\mathrm{e}}=0.01, p<.01, \eta_{\mathrm{p}}^{2}=\right.$ $\left..21 ; F_{2}(2,141)=25.75, M S_{\mathrm{e}}=0.01, p<.01, \eta_{\mathrm{p}}^{2}=.27\right]$. Follow-up univariate ANOVAs with group as the independent variable revealed that the two bilingual groups outperformed the monolingual group on both immediate (Bonferroni post hoc $p \mathrm{~s}<.01$ ) and delayed (Bonferroni post hoc $p$ s $<.05$ ) recall measures, but did not differ from each other. The interaction was driven by stronger differences between monolinguals and the two bilingual groups at immediate testing than at delayed testing. Oneway univariate ANOVAs with group as the independent variable were conducted for immediate recall data versus delayed recall data. Analyses revealed a significant effect of group for immediate recall $\left[F_{1}(2,56)=8.50, p<.01\right.$, $\left.\eta_{\mathrm{p}}^{2}=.23 ; F_{2}(2,141)=22.99, p<.01, \eta_{\mathrm{p}}^{2}=.25\right]$ and a significant, but less robust, effect of group for delayed recall $\left[F_{1}(2,54)=3.18, p<.05, \eta_{\mathrm{p}}^{2}=.11 ; F_{2}(2,141)=\right.$ $\left.3.32, p<.05, \eta_{\mathrm{p}}^{2}=.05\right]$.

Because the two bilingual groups differed in their L2 AoA, it is possible that differences between the two bilingual groups were obscured by AoA differences; therefore, all comparisons between the two bilingual groups were rerun with AoA as a covariate. The results remained the same, with the two bilingual groups demonstrating comparable accuracy rates on both recognition and recall measures.

\section{DISCUSSION}

The objective of this study was to examine whether different types of bilingualism have distinct influences on adults' ability to learn novel words. The results suggest a bilingual advantage, with both bilingual groups outperforming the monolingual group. This bilingual advantage was observed for all performance measures, and it was maintained long-term. Because both groups of bilinguals acquired their two languages early in life, these effects cannot be attributed to bilinguals' enhanced use of classroom learning strategies. Moreover, because we ensured that novel words would be equally unfamiliar to all par- 
ticipants (bilinguals and monolinguals), the bilingual advantage for word learning cannot be attributed to the novel words' overlap with bilinguals' second language (Spanish or Mandarin). Instead, the findings indicate that early experience with two linguistic systems facilitated bilinguals' ability to acquire new words later in life.

The results also indicate that both experience with Spanish and experience with Mandarin facilitated novel word learning. These findings diverge somewhat from the previous work on phonological advantages in bilingual children. Prior research showed that phonological processing in bilinguals is facilitated through acquisition of two languages that share letter-to-phoneme conversion principles; however, bilingual children whose two languages had distinct writing systems did not show metaphonological advantages (see, e.g., Bialystok et al., 2005; Bialystok et al., 2003). In the present study, acquisition of novel phonological information in adults was facilitated through experience with either Spanish or Mandarin to similar degrees. These findings indicate that experience with any two phonological systems early in life facilitates subsequent phonological learning that is independent of the writing systems. In that, the bilingual advantage for novel word learning seems more akin to bilingual advantage effects that have been observed for nonlinguistic tasks (see, e.g., Bialystok et al., 2004; Costa et al., 2008), rather than those that have been observed for linguistic tasks (see, e.g., Bialystok et al., 2005; Bruck \& Genesee, 1995).

The present study informs the search for the mechanisms underlying the bilingual advantage on cognitive and linguistic tasks by suggesting that early experience with two phonological systems leads to improved learning of novel phonological information later in life. Considering word learning within the information-processing framework, where information is encoded, stored, and retrieved, points to a number of potential mechanisms for the bilingual advantage that were observed in the present study. It is possible that the bilingual advantage results from more efficient encoding of phonologically unfamiliar information in bilingual speakers than that in monolingual speakers. Early exposure to two phonological systems may delay the onset of language-specific phonological tuning (see, e.g., Bosch \& Sebastián-Gallés, 2001), and a more tolerant phonological system that persists into adulthood may make bilinguals especially well equipped for encoding unfamiliar phonological information. This explanation of the bilingual advantage can be tested in future research by exposing participants to novel words that are based on familiar phonology.

It is also possible that the bilingual advantage results from bilinguals' increased memory-storage capacity relative to monolinguals. This is precisely the mechanism of the bilingual advantage that was suggested by Papagno and Vallar (1995), who proposed that the bilingual advantage for word learning is rooted in bilinguals' higher working memory capacity. Linking word-learning advantages to working memory is logical, given that prior work has indicated an association between word-learning and workingmemory performance (e.g., Gupta, 2003; Papagno, Valentine, \& Baddeley, 1991; Service, 1992). In the present study, a digit-span task was administered to all participants in order to measure their phonological memory. Interestingly, the measures of word learning and phonological memory diverged. Both bilingual groups outperformed the monolingual group on the word-learning task, yet both bilingual groups performed similarly to the monolingual group on the digit-span task. It appears, therefore, that the bilingual advantage for novel word learning in the present study cannot be accounted for by phonological-memory differences between bilinguals and monolinguals, at least as measured through the digit-span task. Future work that explicitly relates various phonological working memory measures with word-learning performance is necessary before firm conclusions about the role of working memory storage capacity in the development of the bilingual advantage for word learning can be reached.

Lastly, the bilingual advantage on the word-learning task can be traced to a more efficient retrieval of stored information from memory in bilinguals than in monolinguals. This account fits with previous work regarding the effects of bilingualism on inhibitory-control tasks (e.g., Bialystok, 1999; Bialystok et al., 2004; Colzato et al., 2008; Costa et al., 2008). Bilingual language processing is characterized by habitual suppression of words from one language in order to select words from the target language. This pattern appears to facilitate better performance by bilinguals on selective-attention tasks relative to the performance of monolinguals (see, e.g., Bialystok et al., 2004). Word-learning performance may rely on such inhibitory mechanisms. For instance, retrieving English translations for newly learned novel words can be seen as a selectiveattention task in which the target translation must be selected and the alternatives must be inhibited. This account of the bilingual advantage on the word-learning tasks can be tested by modifying the procedure so that the novel word is linked to a novel, rather than a familiar, concept.

To conclude, the results of the present study suggest a general bilingual advantage for novel word learning. This bilingual advantage has been observed previously in adults who have acquired their multiple languages through classroom exposure. Here, we demonstrated a bilingual advantage for word learning in bilinguals who had acquired their two languages early in life through naturalistic immersion. Because word learning is a complex cognitive task, it is likely that a combination of factors yields the bilingual advantage for word learning. Although the mechanisms of the bilingual advantage for word learning demand further experimentation, the present study was successful in demonstrating that acquisition of any two languages early in life facilitates the ability to learn new words in adulthood. Both experience with two related languages (English and Spanish) and experience with two phonologically and orthographically distinct languages (English and Mandarin) yielded an advantage for vocabulary acquisition.

\section{AUTHOR NOTE}

This research was supported in part by NSF Grant BCS0617455 and a Joseph Levin Foundation Scholarship to M.K. and by NSF Grant BCS0418495 and NICHD Grant 1R03HD046952-01A1 to V.M. The 
authors thank Richard Gerrig, Ellen Bialystok, Elisabet Service, and two anonymous reviewers for insightful comments on an earlier version of the manuscript; Henrike Blumenfeld, James Booth, Doris Johnson, and Karla McGregor for helpful suggestions during the course of this work; and Bronwyn Woods, Tina Yao, Swapna Musunuru, and Jenny Garver for assistance at various stages of data collection. Correspondence concerning this article should be addressed to M. Kaushanskaya, Department of Communicative Disorders, University of Wisconsin, 1975 Willow Drive, Madison, WI 53706 (e-mail: kaushanskaya@wisc.edu).

\section{REFERENCES}

BialystoK, E. (1999). Cognitive complexity and attentional control in the bilingual mind. Child Development, 70, 636-644.

Bialystok, E., Craik, F. I. M., Klein, R., \& Viswanathan, M. (2004). Bilingualism, aging, and cognitive control: Evidence from the Simon task. Psychology \& Aging, 19, 290-303.

Bialystok, E., Craik, F. I. M., \& Ryan, J. (2006). Executive control in a modified antisaccade task: Effects of aging and bilingualism. Journal of Experimental Psychology: Learning, Memory, \& Cognition, 32, 1341-1354.

BialystoK, E., LuK, G., \& Kwan, E. (2005). Bilingualism, biliteracy, and learning to read: Interactions among languages and writing systems. Scientific Studies of Reading, 9, 43-61.

Bialystok, E., Majumder, S., \& Martin, M. M. (2003). Developing phonological awareness: Is there a bilingual advantage? Applied Psycholinguistics, 24, 27-44.

Bialystok, E., \& Martin, M. M. (2004). Attention and inhibition in bilingual children: Evidence from the dimensional change card sort task. Developmental Science, 7, 325-339.

Bosch, L., \& Sebastián-Gallés, N. (2001). Evidence of early language discrimination abilities in infants from bilingual environments. Infancy, 2, 29-49.

Bruck, M., \& Genesee, F. (1995). Phonological awareness in young second language learners. Journal of Child Language, 22, 307-324.

Colzato, L. S., Bajo, M. T., van den Wildenberg, W., Paolieri, D., Nieuwenhuis, S., La Heis, W., \& Hommel, B. (2008). How does bilingualism improve executive control? A comparison of active and reactive inhibition mechanisms. Journal of Experimental Psychology: Learning, Memory, \& Cognition, 34, 302-312.
Costa, A., Hernández, M., \& Sebastián-Gallés, N. (2008). Bilingualism aids conflict resolution: Evidence from the ANT task. Cognition, 106, 59-86.

Dunn, L. M., \& Dunn, L. M. (1997). PPVT-III: Peabody picture vocabulary test (3rd ed.). Circle Pines, MN: American Guidance Service.

Ellis, N. C., \& BeAton, A. (1993). Psycholinguistic determinants of foreign language vocabulary learning. Language Learning, 43, 559-617.

GuPTA, P. (2003). Examining the relationship between word learning, nonword repetition, and immediate serial recall in adults. Quarterly Journal of Experimental Psychology, 56A, 1213-1236.

Marian, V., Blumenfeld, H. K., \& Kaushanskaya, M. (2007). The language experience and proficiency questionnaire (LEAP-Q): Assessing language profiles in bilinguals and multilinguals. Journal of Speech, Language, \& Hearing Research, 50, 940-967.

Martínez-Celdrán, E., Fernández-Planas, A. M., \& CarreraSabaté, J. (2003). Castilian Spanish. Journal of the International Phonetic Association, 33, 255-259.

Papagno, C., Valentine, T., \& Baddeley, A. (1991). Phonological short-term memory and foreign-language vocabulary learning. Journal of Memory \& Language, 30, 331-347.

Papagno, C., \& Vallar, G. (1995). Verbal short-term memory and vocabulary learning in polyglots. Quarterly Journal of Experimental Psychology, 48A, 98-107.

SERVICE, E. (1992). Phonology, working memory, and foreign-language learning. Quarterly Journal of Experimental Psychology, 45A, 21-50.

Van Hell, J. G., \& Mahn, A. C. (1997). Keyword mnemonics versus rote rehearsal: Learning concrete and abstract foreign words by experienced and inexperienced learners. Language Learning, 47, 507-546.

Wagner, R. K., Torgesen, J. K., \& Rashotte, C. A. (1999). Comprehensive test of phonological processing: CTOPP. Austin, TX: Pro-Ed, Inc.

WAN, I.-P., \& JAEGER, J. J. (2003). The phonological representation of Taiwan Mandarin vowels: A psycholinguistic study. Journal of East Asian Linguistics, 12, 205-257.

Williams, K. T. (1997). Expressive vocabulary test. Circle Pines, MN: American Guidance Service.

(Manuscript received December 23, 2008; revision accepted for publication March 2, 2009.) 